\title{
Hiding in plain sight: DNA barcoding suggests cryptic species in all 'well-known' Australian flower beetles (Scarabaeidae: Cetoniinae)
}

\author{
Andrew Mitchell ${ }^{\text {Corresp., } 1}$, Christian H Moeseneder ${ }^{1,2}{ }^{\text {, Paul M Hutchinson }}{ }^{3}$ \\ 1 Australian Museum Research Institute, Australian Museum, Sydney, New South Wales, Australia \\ 2 Oceans and Atmosphere Flagship, Commonwealth Scientific and Industrial Research Organisation, St Lucia, Queensland, Australia \\ 3 Quarantine Western Australia, Department of Agriculture and Food Western Australia, Perth, Western Australia, Australia \\ Corresponding Author: Andrew Mitchell \\ Email address: andrew.mitchell@austmus.gov.au
}

DNA barcode data is presented for Australian cetoniine flower beetles to aid with species discovery and guide revisionary taxonomy. Sequences of the COI gene's DNA barcode region were acquired from 284 cetoniine specimens, covering 68 described species and 33 genera. This equates to $48 \%$ of the known species and $83 \%$ of the genera which occur in Australia. Results suggest up to 27 putative undescribed species in our sample, only 11 of which were suspected to be undescribed before this study, leaving 16 unexpected ("cryptic") species. The Australian cetoniine fauna may hence be increased by up to $19 \%$. An unanticipated result of the work is that each of the five most visible and commonly collected Australian cetoniine species, Eupoecila australasiae (Donovan, 1805), Neorrhina punctatum (Donovan, 1805), Glycyphana (Glycyphaniola) stolata (Fabricius, 1781), Chondropyga dorsalis (Donovan, 1805) and Bisallardiana gymnopleura (Fischer, 1823), have unexpectedly high diversity in DNA barcode sequences and were consequently split into multiple clusters, possibly indicating the presence of cryptic species. 
2 Hiding in plain sight: DNA barcoding suggests cryptic species in

3 all 'well-known' Australian flower beetles (Scarabaeidae:

4 Cetoniinae)

5

6 Andrew Mitchell ${ }^{1}$, Christian H. Moeseneder ${ }^{1,2}$, Paul M. Hutchinson ${ }^{3}$

$9{ }^{1}$ Australian Museum Research Institute, Australian Museum, Sydney, New South Wales,

10 Australia

$11{ }^{2}$ Oceans and Atmosphere Flagship, Commonwealth Scientific and Industrial Research

12 Organisation, St Lucia, Queensland, Australia

$13{ }^{3}$ Quarantine Western Australia, Department of Agriculture and Food Western Australia, Perth, 14 Western Australia, Australia

17 Corresponding Author:

Andrew Mitchell ${ }^{1}$

Australian Museum, 1 William Street, Sydney, NSW, 2010, Australia

Email address: andrew.mitchell@austmus.gov.au 


\section{Abstract}

DNA barcode data is presented for Australian cetoniine flower beetles to aid with species discovery and guide revisionary taxonomy. Sequences of the COI gene's DNA barcode region were acquired from 284 cetoniine specimens, covering 68 described species and 33 genera. This equates to $48 \%$ of the known species and $83 \%$ of the genera which occur in Australia. Results suggest up to 27 putative undescribed species in our sample, only 11 of which were suspected to be undescribed before this study, leaving 16 unexpected ("cryptic") species. The Australian cetoniine fauna may hence be increased by up to $19 \%$. An unanticipated result of the work is that each of the five most visible and commonly collected Australian cetoniine species, Eupoecila australasiae (Donovan, 1805), Neorrhina punctatum (Donovan, 1805), Glycyphana (Glycyphaniola) stolata (Fabricius, 1781), Chondropyga dorsalis (Donovan, 1805) and Bisallardiana gymnopleura (Fischer, 1823), have unexpectedly high diversity in DNA barcode sequences and were consequently split into multiple clusters, possibly indicating the presence of cryptic species.

\section{Introduction}

The cosmopolitan scarab beetle subfamily Cetoniinae, or flower beetles, comprises 4,273 species worldwide in 485 genera (Krajčík, 2012). The common species are well-represented in institutional and private collections in Australia, and one early collector, F.P. Dodd, arranged hundreds of colourful specimens in large display frames for exhibition (Monteith, 2010). Despite their visibility, the taxonomy of Australian cetoniines has been somewhat neglected until recent times, with only 10 works in scientific literature and 16 species described in the 65 years from 1944-2009. Previous taxonomic work on Australian fauna is detailed in Moeseneder et al. (2019).

Approximately $75 \%$ of the country's cetoniine species are anthophagous. The adults are pollinators of many tree and shrub species (Williams \& Adam, 1998) and feed on nectar, pollen (Moore 1987), fruit and honey. In the remainder of the species males are often in flight, females are sedentary, and adults are rarely or never found on flowers (Moeseneder et al., 2019). Australian cetoniines are not known to be harmful to agriculture (Moeseneder et al., 2019). The larvae of most species live in and feed on decaying wood and function as organic recyclers, within standing or fallen trees. Much remains to be discovered about the biology of Australian Cetoniinae.

The Australian cetoniine fauna is relatively depauperate, comprising 141 species (Moeseneder et al., 2019), or 3\% of the world fauna on 5\% of the land surface. Twenty-eight of the 40 Australian genera $(70 \%)$ and $90 \%$ of species are endemic to the continent. Three of the twelve cetoniine tribes are represented in Australia: Schizorhinini, Cetoniini and Valgini. The Schizorhinini evolved in situ (Krikken, 1984) and is the continent's most speciose tribe, with 111 described species. The majority of Schizorhinini, however, occur from Malaysia eastward to Melanesia (Allard, 1995a, 1995b; Rigout \& Allard, 1997). 
60

61

62

63

64

65

66

67

68

69

70

71

72

73

74

75

76

77

78

79

80

81

82

83

84

85

86

87

88

89

90

91

92

93

94

95

96

97

98

99

100

While attractive and common species are better known, those with unusual characteristics and those that occur in remote regions were often lumped into unnatural genera, primarily in Schizorhina Kirby, 1825 (e.g. Macleay, 1863; 1861), Diaphonia Newman, 1840 (e.g. Janson, 1873; 1874; 1889) and Pseudoclithria van de Poll, 1886 (e.g. Macleay, 1871). Such oddities have been the focus of the authors' (C.H.M. and P.M.H.) past work (detailed in Moeseneder et al., 2019), describing four new genera and seven new species. Based on the published literature and our own observations, we suspected cryptic species to be present in Diaphonia, Pseudoclithria, Bisallardiana Antoine, 2003, Chondropyga Kraatz, 1880, Chlorobapta Kraatz, 1880 and Glycyphana Burmeister, 1842. This DNA barcoding study is a first step towards resolving these taxonomic issues.

DNA barcoding is a widely used tool in taxonomy, with $>6,000$ papers published (BOLD, 2020) since its inception 17 years ago (Hebert et al., 2003). It has overcome many of its early controversies as methods have matured and its utility in taxonomy, ecology and conservation has become widely appreciated (DeSalle \& Goldstein, 2019). Lepidopterists, in particular, have embraced DNA barcoding as the very large datasets that have been developed for the faunas of North America (Hebert et al., 2010), Europe (Hausmann et al., 2011) and Australia (Hebert et al., 2013) facilitate routine species identification and aid taxonomic research in many families. Much progress is being made with beetles as well, e.g. Hendrich et al. (2015) published 16,000 barcodes for 3,500 European species.

The few DNA-based studies to date that have included the Cetoniinae are summarized in Table 1 (refer to Methods for the search methodology used). Most studies were either higher-level phylogenies which used a single sample per species (e.g. Ahrens et al., 2008; 2011; Gunter et al., 2016; McKenna et al., 2015; Sipek et al., 2016) or studies of a single genus. A notable exception was the DNA barcoding study of Hendrich et al. (2015) which included 70 samples from 14 European cetoniine species. A search of the Barcode of Life Data System (BOLD; Ratnasingham \& Hebert, 2007) Public Data Portal for "Cetoniinae Australia" (on 19 March 2020) revealed only 29 barcodes of Australian cetoniines so far. Fifteen of these were from Gunter (2016) and identified only to genus level. Twelve of the remaining barcodes represent three common species which we sampled in this study. Approximately half of these were identified using the BOLD Identification Engine (IDE). Of the remaining two barcodes, one species had been misidentified at the generic level. None of these 29 sequences were included in our study as they did not add species or DNA diversity to our data set, and we did not have access to the specimens to identify taxa previously identified only to genus level.

Before our submissions, a search in GenBank (10 October 2019) for "Cetoniinae" and ("Cytochrome $c$ oxidase subunit I" or "COI" or "CO1" or "COX1") found 1260 records, of which 47\% are from two genera, Osmoderma Lepeltier \& Serville 1828 and Protaetia Burmeister 1842 . Our submitted records increase this number by $23 \%$.

The goals of this study are to build a foundational DNA barcode library for Australian Cetoniinae with the purpose of aiding the discovery of Australian species, anchoring the process of revising their taxonomy, facilitating identification of larvae and aiding investigations into the little-known biology of Australian cetoniines, particularly through future metabarcoding studies.

Peer] reviewing PDF | (2020:03:47133:1:1:NEW 14 May 2020) 
101 Materials \& Methods

\section{Insect specimens and taxonomy}

103 Our study covers Australia, including its external territories, although of these, cetoniines are

104 known to be present only on Christmas Island and the Cocos (Keeling) Islands. Collecting

105 permits were provided by the Queensland Department of Environment and Science (permit

106 numbers WITF18701717, WITK15549915, W1TK10612112, WITK05498008, TWB/02/2015,

$107 \mathrm{TWB} / 03 \mathrm{~B} / 2012, \mathrm{TWB} / 04 \mathrm{~A} / 2010, \mathrm{TWB} / 27 \mathrm{~B} / 2010, \mathrm{TWB} / 27 \mathrm{~A} / 2008$ and TWB/26/2008), the

108 NSW National Parks and Wildlife Service (permit number SL100610) and the Western Australia

109 Department of Biodiversity, Conservation and Attractions (permit numbers F025000050, 08-

110 000563-2 and SF008817).

111 Images of specimens were taken with a Nikon D5100 camera, a Micro Nikkor $105 \mathrm{~mm}$ macro

112 lens and four 3-Watt LED lights. The camera was controlled by Nikon Camera Control Pro 2

113 version 2.28.2 from a laptop computer. Focus-stacking was performed with a unit built by

114 C.H.M. (Moeseneder, 2017).

115 Male genitalia were removed by separating the abdomen from the thorax by sliding Dumont \#5

116 tweezers in the gap between abdomen and thorax at several points, usually requiring the

117 metatibia to be forced slightly away from the abdomen. The aedeagus was then extracted from

118 the abdomen and the abdomen re-attached with cyanoacrylate glue. The aedeagus was mounted

119 with a micro pin into a small foam piece which was pinned on the same pin as the specimen. A

120 small amount of cyanoacrylate glue was applied where the micro pin pierced the aedeagus to

121 keep it from rotating or being lost. The method allowed rapid extraction without externally

122 visible damage, storage of the aedeagus with the specimen, and three-dimensional inspection of

123 the aedeagus at any time without obscuring any part. For species identification, all collections

124 which are listed in the abbreviations were used.

125 In all but one case, sampled larvae were the progeny of mated and identified beetles held in

126 closed containers. Tissue samples (one rear leg or all legs on one side) were generally taken at

127 L3 stage. These species were easily identified and mostly common. The single exception,

128 MIC60567-002 was an unidentified, wild-collected larva.

129 Abbreviations of institutions and museums:

130 AFBRC - Australian Flower Beetle Research Collection, Redland Bay, Qld, Australia

131 AMS - $\quad$ Australian Museum, Sydney, NSW, Australia

132 ANIC - Australian National Insect Collection, Canberra, Australia

133 CSIRO- Commonwealth Scientific and Industrial Research Organisation

134 DAF - Department of Agriculture and Fisheries, Queensland

135 NHML- Natural History Museum, London, United Kingdom 
136 PMH - Paul Hutchinson, Beckenham, Perth, WA, Australia

137 QM - Queensland Museum, Brisbane, Qld, Australia

138 SAM - $\quad$ South Australian Museum, Adelaide, SA, Australia

139 WAM - Western Australian Museum, Perth, WA, Australia

140 Further abbreviations: ACT - Australian Capital Territory, NSW - New South Wales, NT -

141 Northern Territory, Qld - Queensland, SA - South Australia, Vic. - Victoria, WA - Western

142 Australia.

143 Identifications were based on knowledge of described and undescribed species gained from 1)

144 examination of specimens and images of type material of a large majority of species in the

145 collections listed in Methods and Materials, 2) the original descriptions of all taxa in literature, 3)

146 all published literature on Australian cetoniines, and 4) a database maintained by CHM and PMH

147 which lists current name availability and synonymies.

148 Collection data and images of each specimen were uploaded to BOLD as public project AUCET,

149 Australian Cetoniinae.

150 Where potentially undescribed species are mentioned in this work, they are identified by a code

151 in the format $\mathrm{sp}_{-} \mathrm{xxx} \_\mathrm{chm}$ where the ' $\mathrm{xxx}$ ' is a unique code. Their taxonomy will be resolved in

152 future studies.

153 To find previous taxonomic and phylogenetic studies that produced DNA data for Cetoniinae 154 we: 1) searched for the keywords "Cetoniinae and DNA or molecular" in Web of Science

155 (https://apps.webofknowledge.com), 2) performed a Google search with the same keywords, 3)

156 performed a search of GenBank for Cetoniinae COI sequences, and a subsequent search of

157 Google Scholar for the studies that produced those sequences, and 4) consulted the reference list

158 in each paper that was found.

159 We use the term "well-known species" for our subjective measure of those Australian cetoniine

160 species 1) with high numbers of specimens in collections, 2) which have more often been used to

161 represent the subfamily, for example in literature and displays, 3) with larger numbers of records

162 in The Atlas of Living Australia (http://www.ala.org.au), and 4) which are seen by the public in

163 backyards and parks, and hence reported to museums, mentioned in digital media posts (e.g.

164 Flickr, http://www.flickr.com) and citizen science projects (e.g. QuestaGame,

165 http://www.questagame.com).

\section{DNA barcoding}

167 An initial trial round of sampling from both, archival specimens and those collected within the

168 last approximately 10 years, produced a high rate of unsuccessful DNA extractions. Thereafter,

169 the standardized sampling procedure described below was implemented which increased the

170 success rate of DNA sequencing to $98 \%$. 
171 We sampled one to 12 specimens per species (mean $=3.34$, median $=3)$ maximizing geographic

172

173

174

175

176

177

178

179

180

181

182

183

184

185

186

187

188

189

190

191

192

193

194

195

196

197

198

199

200

201

202

203

204

205

206

207

208

209

210

211 coverage where possible. The small sample size for some species is due to their scarcity and the lack of availability of recent material. Live adult specimens were collected directly into laboratory-grade ethanol and samples for DNA extraction were taken immediately after death. Sampling was performed by removing the rear left leg with forceps, which were sterilized between samples by wiping with a clean tissue, dipping in $100 \%$ ethanol and flaming. A new, sterile surgical blade was used to cut the femur at both apices to exclude the joints. The central part of the femur was cut into two or more fragments to expose muscle tissue. Approximately equal-sized samples were used across all taxa to obtain comparable DNA concentrations. Samples were transferred to a tissue sample plate with sterilized forceps. During this process, all neighbouring wells were kept covered to reduce the chance of contamination. The sampling plate was stored in a freezer at approximately $-12^{\circ} \mathrm{C}$. Exceptions to this sampling protocol were: 1) the 18 specimens collected in flight intercept traps which were killed in a mixture of propylene glycol and water, and transferred to ethanol after approximately 2-4 weeks, and 2) Microvalgus Kraatz, 1883 specimens, where the entire specimen was macerated and used for sequencing. In these cases, the samples were one of a series of specimens collected at the same time, on the same tree and morphologically identical. In each case the series of specimens was kept as reference material.

Since specimen age ranged from 1-22 years, we used the PCR primers and amplification strategy developed by Mitchell (2015) for decades-old insect specimens. In summary, an attempt was made to PCR-amplify a 667-bp fragment of COI. If this was unsuccessful, two shorter overlapping PCR fragments, each approximately $300 \mathrm{bp}$ were amplified, and subsequently reamplified using an internally nested primer on one end. When aligned, the two short fragments yielded $559 \mathrm{bp}$ of contiguous COI sequence within the DNA barcode region. PCR fragments were purified and Sanger-sequenced in both directions on an ABI 3730xl sequencer by Macrogen Inc. (Seoul).

Sequence trace files were assembled, PCR primers were trimmed, and consensus sequences aligned using Geneious 9.1.8 (Kearse et al., 2012). Trace files and consensus sequences were uploaded to BOLD (http://boldsystems.org/) and are available as public project Australian Cetoniinae, project code AUCET, and as dataset DS-AUCET (dx.doi.org/10.5883/DS-AUCET). Sequences were also submitted to GenBank as accession numbers MT323780-MT324061. Note that two sequences were $<200 \mathrm{bp}$ in length and did not receive GenBank accession numbers, but are on BOLD.

The BOLD platform was used for barcode-specific analyses, including the calculation of intraspecific and within-genus interspecific K2P distances (Kimura, 1980), barcode gap analysis and BIN discordance analysis, i.e., comparison of morphology-based species identifications with Barcode Index Numbers (BINs) which are operational taxonomic units (OTUs) derived using RESL clustering (Ratnasingham \& Hebert, 2013). We note, however, that sequences that do not meet all quality criteria, including for length, are not assigned to BINs. Therefore, for a more complete comparison of OTUs based on RESL clustering versus morphospecies, we also performed RESL clustering on all sequences using the "cluster sequences" function on BOLD.

Peer) reviewing PDF | (2020:03:47133:1:1:NEW 14 May 2020) 
212 Finally, we tested for possible isolation by distance within every species, using the Geographic

213 Distance Correlation tool on the BOLD platform, which calculates a Mantel correlation

214 coefficient for geographic distance between sample localities versus K2P distance, and provides

215 a Mantel test $\mathrm{P}$ value.

216 FaBox v. 1.4.2 (Villesen, 2007) was used to edit sequence names. Phylogenetic analyses were

217 performed on the online science gateway CIPRES v. 3.3 (Miller et al., 2010). Partitionfinder v.2

218 (Lanfear et al., 2016) was used to select a partitioning scheme and to select the most appropriate

219 models, which, in all cases, was a single data partition and the General Time Reversible model

220 with Gamma-distributed rates and Invariable sites $(\mathrm{GTR}+\mathrm{G}+\mathrm{I})$. Phylogenetic analyses were

221 performed by Bayesian Inference (BI) using MrBayes v. 3.2.6 (Ronquist et al., 2012) and under

222 maximum likelihood using RAxML v. 8.2.10 (Stamatakis, 2014). The MrBayes analysis was set

223 to run for 20 million generations, with a sample frequency of 1,000 , using 2 runs, setting the

224 number of chains to 4 . The stopping rule was used to end the analysis when the average standard

225 deviation of split frequencies dropped below 0.01, indicating convergence of the chains. The

226 burnin fraction was set to 0.25 . RAxML analysis used the hill climbing algorithm with 1,000

227 rapid non-parametric bootstrap replicates (Felsenstein, 1985). All trees were rooted on Valgini

228 (Microvalgus) since the most comprehensive molecular phylogeny of the subfamily to date

229 (Sipek et al., 2016) placed Valgini, and Trichiini in part, as sister-group to the remaining 10

230 tribes that they sampled.

231

232

233

234

235

236

237

238

239

240

241

242

243

244

245

246

247

248

249

\section{Results}

We obtained DNA barcode data from 284 specimens, of which 256 were adults (90\%) and 28 were larvae. We sampled 68 described species and up to 27 putative undescribed species at an average of 3 specimens per species. Our total of 68 described species includes an unidentified species of Microvalgus which is likely to be a described species. All taxa are represented by at least one adult and none are represented only by larvae.

Two hundred and forty-five sequences $(86 \%)$ are BARCODE standard compliant, defined as $>$ $486 \mathrm{bp}$ in length, with two or fewer ambiguous bases and with at least two high-quality sequence trace files uploaded. Only six sequences were less than $300 \mathrm{bp}$ in length.

Mean specimen age at DNA extraction was 4.2 years, although for the first batch of 94 samples the mean age was 7.4 years. The oldest sample to yield barcode-standard compliant data was 22.6 years old.

Bayesian Inference was completed after 18,625,000 generations when the average standard deviation of split frequencies reached 0.009997. The structure of the BI tree is summarized in Fig. 1, with strongly supported branches (posterior probabilities (PP) $\geq 0.99$ and bootstrap percentages (BP) from the RAxML $\geq 95 \%$ ) indicated by asterisks. The complete BI tree is shown in Figs. 2-7 and the complete RAxML tree is provided as supplementary Fig. S1.

Eleven genera were represented by a single species in our data set, including seven monotypic genera (Phyllopodium Schoch, 1895, Octocollis Moeseneder \& Hutchinson, 2012, Lenosoma 
250 Kraatz, 1880, Stenopisthes Moser, 1913, Hemipharis Burmeister, 1842, Neoclithria van de Poll, 251 1886, Micropoecila Kraatz, 1880) and four additional genera (Mycterophallus van de Poll, 1886,

252 Poecilopharis Kraatz, 1880, Evanides Thomson, 1880, Storeyus Hasenpusch \& Moeseneder, 253 2009). In all six cases where these species had multiple samples, the species were recovered as 254 monophyletic and distinct from other species.

255 Of the remaining 22 genera, for which multiple species were sampled, half were recovered as

256

257

258

259

260

261

262

263

264

265

266

267

268

269

270

271

272

273

274

275

276

277

278

279

280

281

282

283

284

285

286

287

monophyletic. These are listed with the number of species sampled and number of specimens $(n)$ sampled in parentheses: Microvalgus (4 spp., $n=13)$, Ischiopsopha Gestro, 1874 (2 spp., $n=8)$, Lomaptera Gory \& Percheron, 1833 (2 spp., $n=5)$, Schizorhina (2 spp., $n=6)$, Navigator Moeseneder \& Hutchinson, 2016 ( 2 spp., $n=5$ ), Lyraphora Kraatz, 1880 (3 spp., $n=11$ ), Tapinoschema Thomson, 1880 ( 3 spp., $n=12$ ), Bisallardiana (10 spp., $n=31)$, Neorrhina Thomson, 1878 (2 spp., $n=11$ ), Chlorobapta (3 spp., $n=11$ ) and Metallesthes Kraatz, 1880 (4 spp., $n=16)$.

RESL cluster analysis grouped sequences into 100 OTUs, with 32 of these being singletons. There were 21 singleton species, and the remaining 11 singleton OTUs represented divergent lineages within species. RESL clustering split 13 species, some of them into as many as 4 OTUs, as summarised in Table 2.

Two BINs contained multiple species. Firstly, the BIN containing Hemichnoodes mniszechi (Janson, 1873), H. parryi (Janson, 1873) and Diaphonia sp_dnul_chm (Fig. S1). However, D. luteola, placed in the same cluster in both trees, was not included in the BIN analysis. In the separate RESL clustering analysis, these four species were recovered as separate OTUs. Secondly, the BIN containing both Glycyphana (Caloglycyphana) papua (Wallace, 1867) and G. (Caloglycyphana) pulchra (Macleay, 1871) (maximum within-OTU distance $=1.57 \%$ ).

The Geographic Distance Correlation test was significant $(\mathrm{p} \leq 0.05)$ for only three species (Ischiopsopha wallacei (Thomson, 1857), Metallesthes anneliesae Moeseneder \& Hutchinson, 2014, Glycyphana stolata) and highly significant $(\mathrm{p} \leq 0.01)$ for a single species, Chondropyga dorsalis.

Larval specimens, indicated by ' $L$ ' after the species name in all Figures, were reared progeny from mated adult specimens, and were placed with the correct species. There was a single wildcollected larva (MIC60567-002) and it was identified by barcoding as Hemichnoodes mniszechi.

\section{Discussion}

This preliminary study reports DNA barcode data for 68 described species from 33 genera, representing $48 \%$ of currently known Australian species and $83 \%$ of the genera (141 described species in 40 genera; Moeseneder et al., 2019; Hutchinson \& Moeseneder, 2019). Our goal is a comprehensive DNA barcode dataset, and complementary nuclear gene and morphological data, to address both species-level and higher-level relationships of the Australian cetoniines, facilitating integrative revisionary taxonomy. Here we recognise likely undescribed species and note cases of likely generic misassignment of species but refrain from making taxonomic 
288

289

290

291

292

293

294

295

296

297

298

299

300

301

302

303

304

305

306

307

308

309

310

311

312

313

314

315

316

317

318

319

320

321

322

323

324

325

326

327

decisions, as that would require careful and comprehensive generic revisions, which are beyond the scope of the current study.

In general, there was concordance between morphology-based identifications and barcode-based clustering. This concordance is not obvious since RESL clustering split many species and produced 100 OTUs. However, our preliminary morphological investigations suggest that in addition to the 68 described species we sampled, the 100 OTUs include up to 27 undescribed species.

Of the 27 possible undescribed species, five were known to us previously and are easily distinguished morphologically, six were suspected but with some uncertainty due to their similarity to described species, and 16 were completely unexpected (potential "cryptic species") and were only revealed by their DNA barcodes. Their morphological similarity to described species is striking, and further work, including analysis of nuclear genes (e.g., Raupach et al., 2010) and male genitalia from a larger series of specimens, is needed to rigorously assess their taxonomic status. The number of undescribed species hence may represent a potential increase to the size of the Australian fauna of $12-19 \%$.

There was one OTU that contained more than one species: Glycyphana (Caloglycyphana) pulchra plus G. (Caloglycyphana) papua, however, these species had $1.57 \%$ distance between them and were clearly separated in the trees.

While Barcode Index Numbers (BINs) are calculated by BOLD using the RESL clustering algorithm, sequences on BOLD must meet criteria such as minimum sequence length and quality to be included in a BIN, thus only 252 sequences were placed into BINs. We therefore also performed a separate RESL clustering analysis on the complete 284 sequence dataset to obtain OTUs. The three differences between these analyses were: 1) both species of Hemichnoodes Kraatz, 1880, plus Diaphonia "sp dnul chm" were assigned to a single BIN (D. luteola (Janson, 1873) was not assigned to any BIN), while the cluster analysis split these four taxa into separate OTUs corresponding to their morphological identification. Relationships among these taxa are discussed below. 2) Dilochrosis balteata was placed in a single BIN but split into two OTUs with $2.15 \%$ distance between them. 3) Eupoecila australasiae was divided into two BINs with $2.71 \%$ distance between them, but comprised a single OTU.

The significant Geographic Distance Correlation tests, on the whole, reflect sampling of very widely separated populations. For Ischiopsopha wallacei, this reflects the separation of samples from Sabai and Dauan Islands, within $5 \mathrm{~km}$ of Papua New Guinea, and samples from approximately $800 \mathrm{~km}$ south in Queensland. Glycyphana stolata samples were collected from Dauan Island to the Brisbane region $>2,200 \mathrm{~km}$ to the south. In Metallesthes anneliesae, the pattern is more subtle as the seven specimens were collected within an $80 \mathrm{~km}$ radius of each other, some $200 \mathrm{~km}$ west of Brisbane, and the most distinct sequence, a separate BIN, is one on the northwestern perimeter of the samples' distribution. The only highly significant test result was for Chondropyga dorsalis, where the 12 specimens were collected within only $70 \mathrm{~km}$ of each other in Southeast Queensland in varying habitat types. An attempt at finding unique, easily visible characters for each group is ongoing. 
328

329

330

331

332

333

334

335

336

337

338

339

340

341

342

343

344

345

346

347

348

349

350

351

352

353

354

355

356

357

358

359

360

361

362

363

364

365

366

While we do not expect a small and rapidly evolving fragment of a single mitochondrial gene to yield a robust phylogeny of the Cetoniinae, phylogenetic analysis of DNA barcodes is likely to give a good indication of relationships among closely related species, to provide a guide to where undescribed taxa should be placed, and suggest where further evidence is needed on supraspecific relationships. The discussion below is meant in that context, acknowledging the limited deeper phylogenetic utility of DNA barcodes.

Microvalgus is a diverse genus (approximately 51 described species worldwide, 16 in Australia) and poorly studied in Australia. We sampled four species, one of which we could not definitively identify and have called Microvalgus "sp. mvalg4 chm" (Fig. 2). Based on current results, we expect DNA barcoding to be useful for revising this group in future.

In the most well-known Australian cetoniine species, Eupoecila australasiae, Neorrhina punctatum, Glycyphana stolata, Chondropyga dorsalis and Bisallardiana gymnopleura, we found high levels of DNA diversity. While this is not unusual for DNA barcoding studies, e.g. in Elateridae (Oba et al., 2015) and stemborer moths (Lee et al., 2019), our preliminary morphological examination of the species implies that these high levels of COI diversity are for the most part correlated with morphological diversity. This suggests that many of these OTUs may in fact represent undescribed species. Further cases of discordance between prior expectations based on current taxonomy and DNA barcoding results are detailed below.

Trichaulax (4 spp., $n=11$ ) was rendered paraphyletic by the insertion of Lenosoma fulgens ( 1 spp., $n=3$ ) (Fig. 3). Chondropyga (4 spp., $n=20$ ) was rendered paraphyletic by the insertion of Pseudoclithria hirticeps (Macleay, 1871) (1 sp., $n=1)$ (Fig. 3). Pseudoclithria hirticeps, the type species of Pseudoclithria, is placed incorrectly and likely belongs in genus Chondropyga.

However, as we sampled only a single specimen of $P$. hirticeps this result requires confirmation with data from further specimens and genes.

The lineage containing Dilochrosis (4 spp., $n=27$ ) had Glycyphana pulchra/G. papua (2 spp., $n$ $=4$ ) embedded within it in the Bayesian tree (Fig. 4). The RAxML tree was similar, except that Protaetia (Protaetia) fusca (Herbst, 1790) $(n=6)$ was also embedded with Dilochrosis, as sister group to the two Glycyphana species (Fig. S1). However, based on morphological evidence, the length of the branch subtending G. pulchra/G. papua and the instability of these nodes when analysed by maximum likelihood methods, it appears unlikely that these placements reflect true phylogenetic affinities, and further evidence is needed to resolve these questions.

Glycyphana was consistently split into two distantly related groups, one containing the closely related G. (Caloglycyphana) pulchra and G. (Caloglycyphana) papua, merged into a single BIN (Fig. 4), and the other containing G. (Glycyphaniola) brunnipes (Kirby, 1818) and G. (Glycyphaniola) stolata (Figs. 5, 6). If confirmed by future phylogenetic analysis of nuclear genes, this interesting result could require the elevation of one of the subgenera to a separate genus. Glycyphana brunnipes is split into two BINs while G. stolata is split into four BINs. Bacchus (1974) split G. stolata into three forms. Substantial further integrative taxonomic work is required to reassess species boundaries in these species complexes. 
367 Neoclithria (1 sp., $n=3$ ) is embedded within Clithria (3 spp., $n=7$ ) (Fig. 6), and Micropoecila 368 (1 sp., $n=2)$ is embedded within Eupoecila (3 spp., $n=12)$ (Fig. 6). Thus, both Neoclithria and 369 Micropoecila may need to be synonymised with the genera they are placed within.

370 Relationships among Diaphonia, Aphanesthes Kraatz, 1880, Hemichnoodes, Pseudoclithria and

371

372

373

374

375

376

377

378

379

380

381

382

383

384

385

386

387

388

389

390

391

392

393

394

395

396

397

398

399

400

401

402

403

404

405

406
Metallesthes were complex (Figs. 6, 7). There was moderate to strong support, a Bayesian posterior probability (PP) of 0.99 and maximum likelihood bootstrap percentage (BP) of $65 \%$, for a clade including Aphanesthes succinea (Hope, 1844) $(n=4)$, Diaphonia $(3$ spp., $n=6)$ and Hemichnoodes ( 2 spp., $n=6$ ). There was weaker support (PP of 0.95 , BP $<50 \%$ ) for the sistergroup to the above clade, comprising A. pullata (Janson, 1873) $(n=3)$, “A. sp_aisa chm” (a possible undescribed species, $n=1$ ), Pseudoclithria (5 spp., $n=13$ ) excluding $P$. hirticeps (mentioned above) and Metallesthes.

Aphanesthes "sp_aisa_chm" appears to share similarities with Aphanesthes pullata and A. trapezifera (the latter species was not DNA barcoded). Hence its placement within Diaphonia, albeit without statistical support, is unexpected and its affinities might be better resolved by nuclear gene data. In contrast, Aphanesthes succinea has several characters not shared with other described Aphanesthes and we expected it to be separated from congeners in the trees. However, where it is placed in our phylogeny, with Diaphonia xanthopyga, appears questionable and this will require a close examination of morphological characters. The grouping of Diaphonia luteola and D. "sp_dnul_chm" with Hemichnoodes is surprising as well because the male genital construction in Hemichnoodes is unique. In the next phase of the molecular project we intend to sample further genes and Australian taxa to assist in resolving these questions.

The remaining seven genera that constitute the Australian cetoniine fauna were not sampled because no recent material was available for DNA sequencing. These are Aurum Hutchinson \& Moeseneder, 2019, Axillonia Krikken, 2018, Grandaustralis Hutchinson \& Moeseneder, 2013, Macrotina Strand, 1934, Territonia Krikken, 2018, Chalcopharis Heller, 1903 and

Charitovalgus Kolbe, 1904. The first four of these genera are monospecific and the last two are represented in Australia by a single species each.

In the absence of either nuclear gene data or robust morphological studies of more specimens, we stopped short of drawing firm conclusions about species boundaries in this study. This is because COI-based barcoding can overestimate the number of species in widely dispersed taxa (Klimov et al., 2019) due to the effects of incomplete lineage sorting, and nuclear inserts of mtDNA fragments (NUMTs). Also, Wolbachia infection can complicate COI-based species delimitation, through creating cytoplasmic incompatibility, or by introgression and selective sweeps (Smith et al., 2012).

Despite the uncertainties mentioned above, the barcode fragment of COI yields an unexpectedly robust tree topology. This suggests that complete mitochondrial genomes would provide useful data for analysing Cetoniinae phylogeny. Given that complete mitochondrial genomes plus complete nuclear ribosomal cistrons can be obtained by genome skimming (Coissac et al., 2016) we suggest that approach would be a profitable strategy for further investigation of both the phylogeny of Cetoniinae and species delimitation.

Peer] reviewing PDF | (2020:03:47133:1:1:NEW 14 May 2020) 
407 Once a DNA barcode library has been established for a given taxon, there are many possible

408

409

410

411

412

413

414

415

416

417

418

419

420

421

422

423

424

425

426

427

428

429

430

431

432

433

434

435

436

437

438

439

440

441

442

applications, including identifying field-collected larvae to uncover species biology, identifying pests, biodiversity assessment and species monitoring, untangling food webs, and so on (Mitchell, 2008). In addition to barcoding representative larvae reared from controlled matings between collected adults, we also applied barcode data to identify an unknown larva, which turned out to be Hemichnoodes mniszechi. This approach to larval identification also makes larval morphological characters now accessible for description and diagnosis.

Development and refinement of DNA barcode libraries facilitates ecological study by anchoring environmental DNA datasets and linking them with robust taxonomy. Such metabarcoding studies may soon revolutionize modern biodiversity surveys (Ruppert et al., 2019) and robust DNA barcode libraries underpin that potential.

\section{Conclusions}

We produced a DNA barcode dataset for Australian flower beetles that includes approximately half of the country's species. We found that DNA barcodes provide species-level resolution in almost all cases. The high levels of DNA diversity were unexpected within many species, and preliminary morphological investigations suggest that there may be as many as 27 undescribed species in our dataset. Further integrative taxonomic work, incorporating COI-based DNA barcoding, nuclear gene data and detailed morphological investigations, are needed to better understand the diversity of Australian Cetoniinae and to document and describe numerous undescribed species.

\section{Acknowledgements}

We thank Michael Raupach and two anonymous reviewers for their suggestions which improved the manuscript. We are very grateful to the following people for their assistance. Jack Hasenpusch (Australian Insect Farm, Innisfail, Qld) for donating many specimens to the AFBRC collection. Dr. Christine Lambkin and Susan Wright (QM) for guidance on various topics, collecting permits, loans and assistance with specimens. Dr. Geoff Monteith (QM) for ecological information and flight intercept traps. For specimen loans: Cate Lemann and Tom Weir (ANIC), Derek Smith (AM), Justin Bartlett (DAF), Dr Nikolai Tatarnic and Brian Hanich (WAM), Andras Szito (DAFWA), Peter Hudson (SAM), Dr. Max Barclay and Beulah Garner (NHML). For fieldwork and donations: Adam and Matthew Yates (Alice Springs, NT), Allen Sundholm (Turrella, NSW), Mark Hura (Parafield Gardens, SA), Geoff Walker (Murrumbeena, Vic.) and David Baume (Cairns, Q1d). Glen Smith (Duaringa, Q1d) and Lindsay Popple (Cairns, Qld) for ecological observations. Melissa Syme (DAF) for access to parks. For access to their private properties: Tracey Rosser (Numinbah, NSW), Michael Corke (Numinbah, NSW) and Selwyn Podlich (Coulson, Qld). Sabine Moeseneder (Redland Bay, Qld) for assistance with fieldwork. Dr. Nicole Gunter (Cleveland Museum of Natural History, Cleveland, Ohio, USA) for additional 
443 information on specimens. Richard Zietek (Cabalaba, Qld) for specimens and loans. Dr. Eva 444 Plaganyi-Lloyd (CSIRO) for supporting excursions via awards.

\section{References}

446 Allard V (1995a) Les Coléoptères du Monde. Volume 23: Schizorhinini 1. Sciences Nat, Venette, 447 France. $152 \mathrm{pp}$.

448 Allard V (1995b) Les Coléoptères du Monde. Volume 24: Schizorhinini 2. Sciences Nat, Venette, 449 France. $136 \mathrm{pp}$.

450 Bacchus ME (1974) A revision of the Australian species of the genus Glycyphana

451 Burmeister (Coleoptera: Scarabaeidae). Journal of the Australian Entomological Society 13:

452 111-128.

453 BOLD (2020) Barcode of Life Data Systems, Publication Portal.

454 http://www.boldsystems.org/index.php/Public_Publication_BibliographySearch (Accessed 27

455 April 2020).

456 Coissac E, Hollingsworth PM, Lavergne S, Taberlet P (2016) From barcodes to genomes:

457 extending the concept of DNA barcoding. Molecular Ecology 25(7): 1423-1428.

458 DeSalle R, Goldstein P (2019) Review and interpretation of trends in DNA barcoding. Frontiers 459 in Ecology and Evolution 7: 302.

460 Felsenstein, J (1985) Confidence limits on phylogenies: an approach using the bootstrap.

461 Evolution 39(4): 783-791.

462 Gunter NL, Weir TA, Slipinski A, Bocak L, Cameron SL (2016) If dung beetles (Scarabaeidae:

463 Scarabaeinae) arose in association with dinosaurs, did they also suffer a mass co-extinction at the 464 K-PG boundary? PLoS ONE 11: e0153570.

465 Hasenpusch J, Moeseneder C (2009) Storeyus, a new genus and Storeyus pseudodipterus, a new 466 species of Cetoniinae (Coleoptera: Scarabaeidae) from Australia, with a redescription of 467 Lenosoma Kraatz. Australian Entomologist 36: 221-234.

468 Hausmann A, Haszprunar G, Segerer AH, Speidel W, Behounek G, Hebert PD (2013) Now 469 DNA-barcoded: the butterflies and larger moths of Germany. Spixiana 34(1): 47-58.

470 Hebert PD, Cywinska A, Ball SL, Dewaard JR (2003) Biological identifications through DNA 471 barcodes. Proceedings of the Royal Society of London. Series B: Biological Sciences 270: 313472321.

473 Hebert PD, DeWaard JR, Landry JF (2010) DNA barcodes for 1/1000 of the animal kingdom. 474 Biology Letters 6(3): 359-362. 
475 Hebert PD, DeWaard JR, Zakharov EV, Prosser SW, Sones JE, McKeown JT, Mantle B, La 476 Salle J (2013) A DNA 'Barcode Blitz': Rapid digitization and sequencing of a natural history 477 collection. PloS ONE 8(7): e68535.

478 Hutchinson P, Moeseneder C (2019) Aurum, a new monotypic genus of Cetoniinae (Coleoptera:

479 Scarabaeidae) endemic to Western Australia, Australia. Zootaxa 4683: 277-285.

480 Hutchinson P, Moeseneder C (2013) Grandaustralis, a new genus and Grandaustralis

481 boomerang, a new species of Cetoniinae (Coleoptera Scarabaeidae) from Western Australia.

482 Zootaxa 3669: 17-26.

483 Kearse M, Moir R, Wilson A, Stones-Havas S, Cheung M, Sturrock S, Buxton S, Cooper A, 484 Markowitz S, Duran C, Thierer T, Ashton B, Meintjes P, Drummond A (2012) Geneious Basic:

485 an integrated and extendable desktop software platform for the organization and analysis of 486 sequence data. Bioinformatics 28: 1647-1649.

487 Kimura M (1980) A simple method for estimating evolutionary rate of base substitutions through 488 comparative studies of nucleotide sequences. Journal of Molecular Evolution 16: 111-120.

489 Klimov PB, Skoracki M, Bochkov AV (2019) Cox1 barcoding versus multilocus species 490 delimitation: validation of two mite species with contrasting effective population sizes. Parasites 491 and Vectors 12(1): 8.

492 Krajčík M (2012) Checklist of the world Scarabaeoidea. Animma.X 5: 1-278.

493 Krikken J (1984) A new key to the suprageneric taxa in the beetle family Cetoniidae, with 494 annotated lists of the known genera. Zoologische Verhandelingen 210: 1-75.

495 Krikken J (2018) Two new genera of Australian flower chafers, with an annotated overview of 496 their relatives (Coleoptera: Scarabaeidae: Cetoniinae). Haroldius 5: 1-36.

497 Lanfear R, Frandsen PB, Wright AM, Senfeld T, Calcott B (2016) PartitionFinder 2: new 498 methods for selecting partitioned models of evolution for molecular and morphological 499 phylogenetic analyses. Molecular Biology and Evolution 34: 772-773.

500 Lee TRC, Anderson SJ, Tran-Nguyen LTT, Sallam N, Le Ru BP, Conlong D, Powell K, Ward

501 A, Mitchell A (2019) Towards a global DNA barcode reference library for quarantine

502 identifications of lepidopteran stemborers, with an emphasis on sugarcane pests. Scientific

503 Reports 9: 7039.

504 Miller MA, Pfeiffer W, Schwartz T (2010) Creating the CIPRES Science Gateway for inference 505 of large phylogenetic trees. Gateway Computing Environments Workshop (GCE), New Orleans, 506 LA, USA. IEEE, 1-8.

507 Mitchell A (2008) DNA barcoding demystified. Australian Journal of Entomology 47(3): 169508173.

509 Mitchell A (2015) Collecting in collections: a PCR strategy and primer set for DNA barcoding of 510 decades-old dried museum specimens. Molecular Ecology Resources 15: 1102-1111. 
511 Moeseneder C (2017) Focus-stacking macro photography system for around $\$ 1,200$. Scarabs 83 :

$5121-7$.

513 Moeseneder C, Weir T, Lemann C, Hutchinson P (2019) 34. Scarabaeidae: Cetoniinae Leach,

514 1815. In Slipinski A \& Lawrence J (eds.) Australian Beetles Volume 2 Archostemata,

515 Myxophaga, Adephaga, Polyphaga (part). CSIRO Publishing. 531-553. pl. 73-76.

516 Moeseneder C, Hutchinson PM (2016) Navigator, a new endemic genus of Cetoniinae

517 (Coleoptera: Scarabaeidae) from Australia with descriptions of two new species and behavioural

518 studies. Zootaxa 4173: 530-556.

519 Moeseneder C, Hutchinson P, Lambkin C (2014) Revision of the genus Metallesthes Kraatz and 520 description of Metallesthes anneliesae, a new species of Cetoniinae (Coleoptera: Scarabaeidae)

521 from Queensland and New South Wales, Australia. Zootaxa 3881: 301-327.

522 Moeseneder C, Hutchinson P (2012) Octocollis, a new genus and Octocollis setosus, a new

523 species of Cetoniinae (Coleoptera: Scarabaeidae) from Queensland, Australia. Zootaxa 3557:

$524 \quad 40-48$.

525 Monteith G (2010) The butterfly man of Kuranda: Frederick Parkhurst Dodd. Queensland 526 Museum, South Brisbane, Australia. 46 p.

527 Moore B (1987) A Guide to the Beetles of South-Eastern Australia. Australian Entomological

528 Press, Greenwich, NSW.

529 Oba Y, Ôhira H, Murase Y, Moriyama A, Kumazawa Y (2015) DNA Barcoding of Japanese

530 Click Beetles (Coleoptera, Elateridae). PLoS ONE 10: e0116612.

531 Ratnasingham S, Hebert PDN (2007) BOLD: The Barcode of Life Data System

532 (www.barcodinglife.org). Molecular Ecology Notes 7: 355-364.

533 Ratnasingham S, Hebert PDN (2013) A DNA-Based Registry for All Animal Species: The 534 Barcode Index Number (BIN) System. PLoS ONE 8: e66213.

535 Raupach MJ, Astrin JJ, Hannig K, Peters MK, Stoeckle MY, Wägele JW (2010) Molecular 536 species identification of Central European ground beetles (Coleoptera: Carabidae) using nuclear 537 rDNA expansion segments and DNA barcodes. Frontiers in Zoology 7(1): 26.

538 Rigout J, Allard V (1997) Schizorhinini 3. The beetles of the World Volume 25. Hillside Books, 539 Canterbury, Great Britain. 128 pp.

540 Ronquist F, Teslenko M, van der Mark P, Ayres DL, Darling A, Höhna S, Larget B, Liu L, 541 Suchard MA, Huelsenbeck JP (2012) MrBayes 3.2: efficient Bayesian phylogenetic inference 542 and model choice across a large model space. Systematic Biology 61: 539-542.

543 Ruppert KM, Kline RJ, Rahman MS (2019) Past, present, and future perspectives of 544 environmental DNA (eDNA) metabarcoding: A systematic review in methods, monitoring, and 545 applications of global eDNA. Global Ecology and Conservation 10: e00547. 
546 Šípek P, Fabrizi S, Eberle J, Ahrens D (2016) A molecular phylogeny of rose chafers Coleoptera: 547 Scarabaeidae: Cetoniinae) reveals a complex and concerted morphological evolution related to

548 their flight mode. Molecular Phylogenetics and Evolution 101: 163-175.

549 Smith MA, Bertrand C, Crosby K, Eveleigh ES, Fernandez-Triana J, Fisher BL, Gibbs J, 550 Hajibabaei M, Hallwachs W, Hind K, Hrcek J, Huang DW, Janda M, Janzen DH, Li Y, Miller 551 SE, Packer L, Quicke D, Ratnasingham S, Rodriguez J, Rougerie R, Shaw MR, Sheffield C, 552 Stahlhut JK, Steinke D, Whitfield J, Wood M, Zhou X (2012) Wolbachia and DNA barcoding 553 insects: patterns, potential, and problems. PLoS One 7(5): e36514.

554 Stamatakis A (2014) RAxML version 8: A tool for phylogenetic analysis and post-analysis of 555 large phylogenies. Bioinformatics 30: 1312-1313.

556 Svensson GP, Oleksa A, Gawroński R, Lassance J, Larsson MC (2009) Enantiomeric

557 conservation of the male-produced sex pheromone facilitates monitoring of threatened European 558 hermit beetles (Osmoderma spp.). Entomologia Experimentalis et Applicata 133: 276-282.

559 Villesen P (2007) FaBox: an online toolbox for FASTA sequences. Molecular Ecology Notes 7: $560965-968$.

561 Vondracek D, Fuchsova A, Ahrens D, Kral D, Sipek P (2018) Phylogeography and DNA-based 562 species delimitation provide insight into the taxonomy of the polymorphic rose chafer Protaetia 563 (Potosia) cuprea species complex (Coleoptera: Scarabaeidae: Cetoniinae) in the Western 564 Palearctic. PLOS ONE 13: e0192349.

565 Williams GA, Adam P (1998) Pollen loads collected from large insects in Australian subtropical 566 rainforests. Proceedings of the Linnean Society of New South Wales 120: 49-67.

567 Zauli A, Carpaneto GM, Chiari S, Mancini E, Nyabuga FN, Redolfi De Zan L, Romiti F, 568 Sabbani S, Audisio PA, Hedenström E, Bologna MA, Svensson GP (2016) Assessing the 569 taxonomic status of Osmoderma cristinae (Coleoptera: Scarabaeidae), endemic to Sicily, by 570 genetic, morphological and pheromonal analyses. Journal of Zoological Systematics and 571 Evolutionary Research 54: 206-214.

572 


\section{Figure 1}

Bayesian phylogenetic tree for all data.

Branches are collapsed to illustrate genus-level relationships. Microvalgus was treated as the outgroup. Asterisks indicate nodes with strong support from both Bayesian posterior probabilities ( $P P \geq 0.99$ ) and maximum likelihood bootstrap percentage (BP $\geq 95$ ). Closed circles indicate nodes with strong support under only one of these methods. 


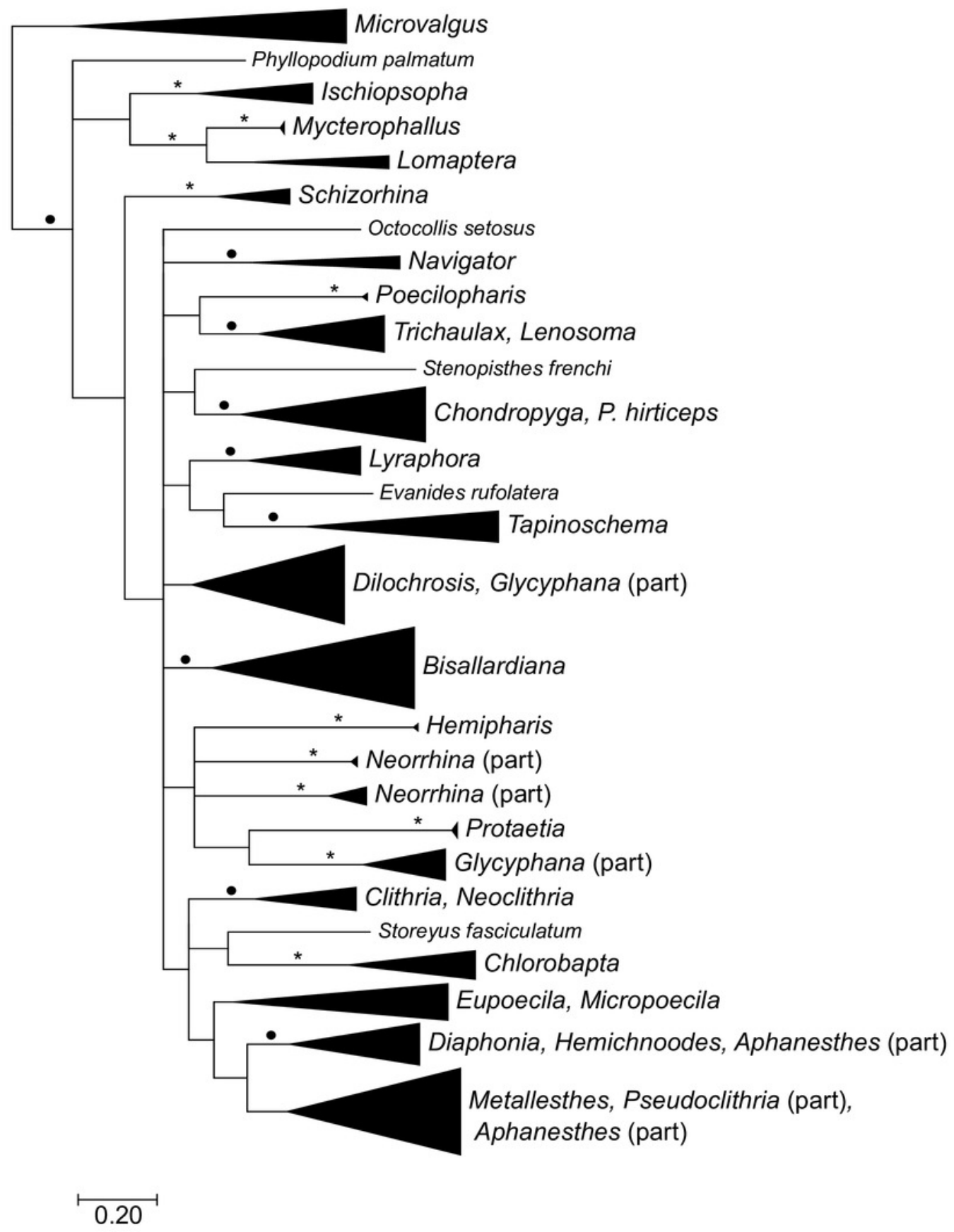


Figure 2

Complete Bayesian tree, part 1 of 6.

Support values (posterior probabilities) are shown at nodes only if $\geq 0.70$. Closed circles indicate taxa whose placement in the tree was unexpected, rendering another genus paraphyletic. 


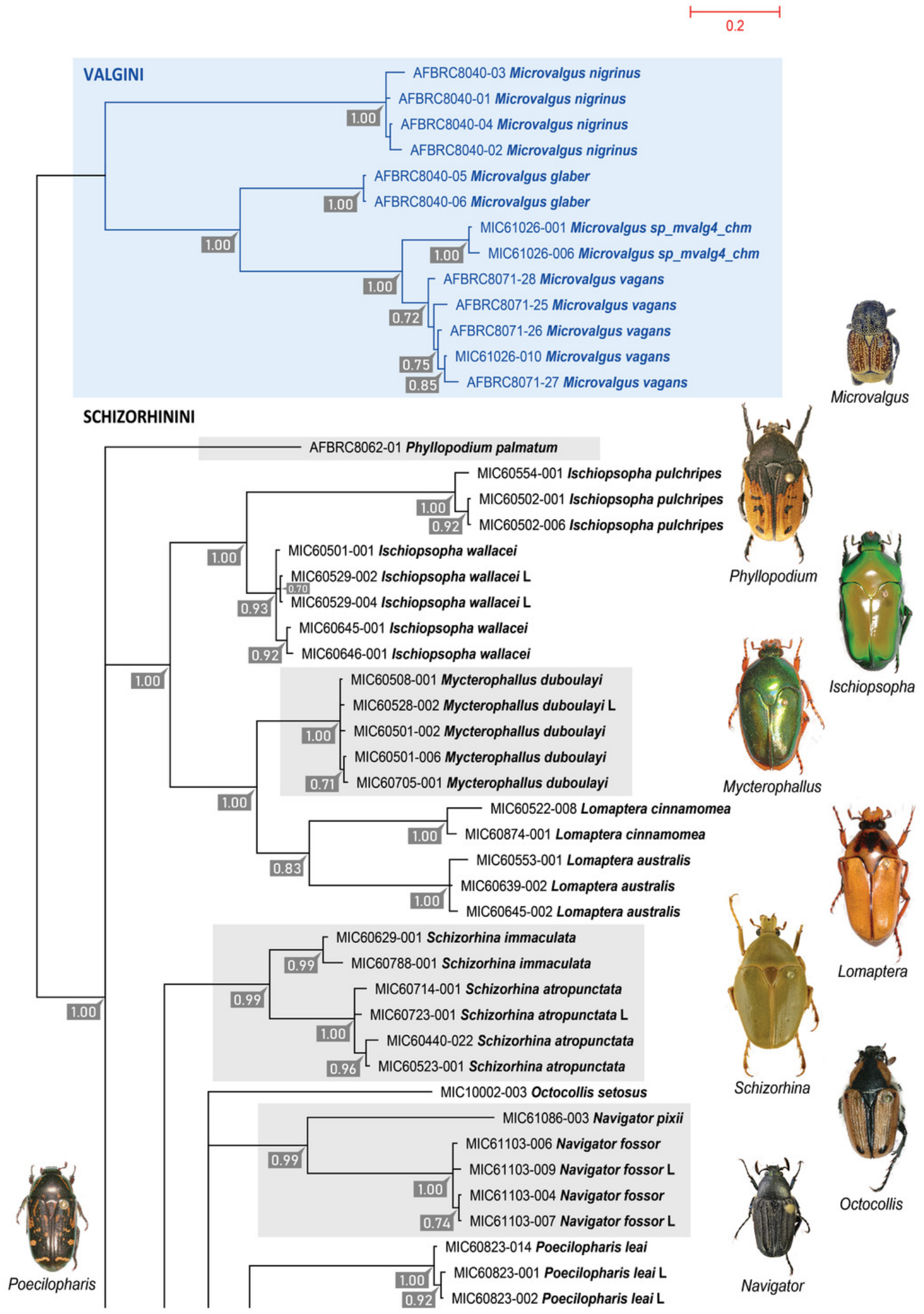


Figure 3

Complete Bayesian tree, part 2 of 6.

Support values (posterior probabilities) are shown at nodes only if $\geq 0.70$. Closed circles indicate taxa whose placement in the tree was unexpected, rendering another genus paraphyletic. 


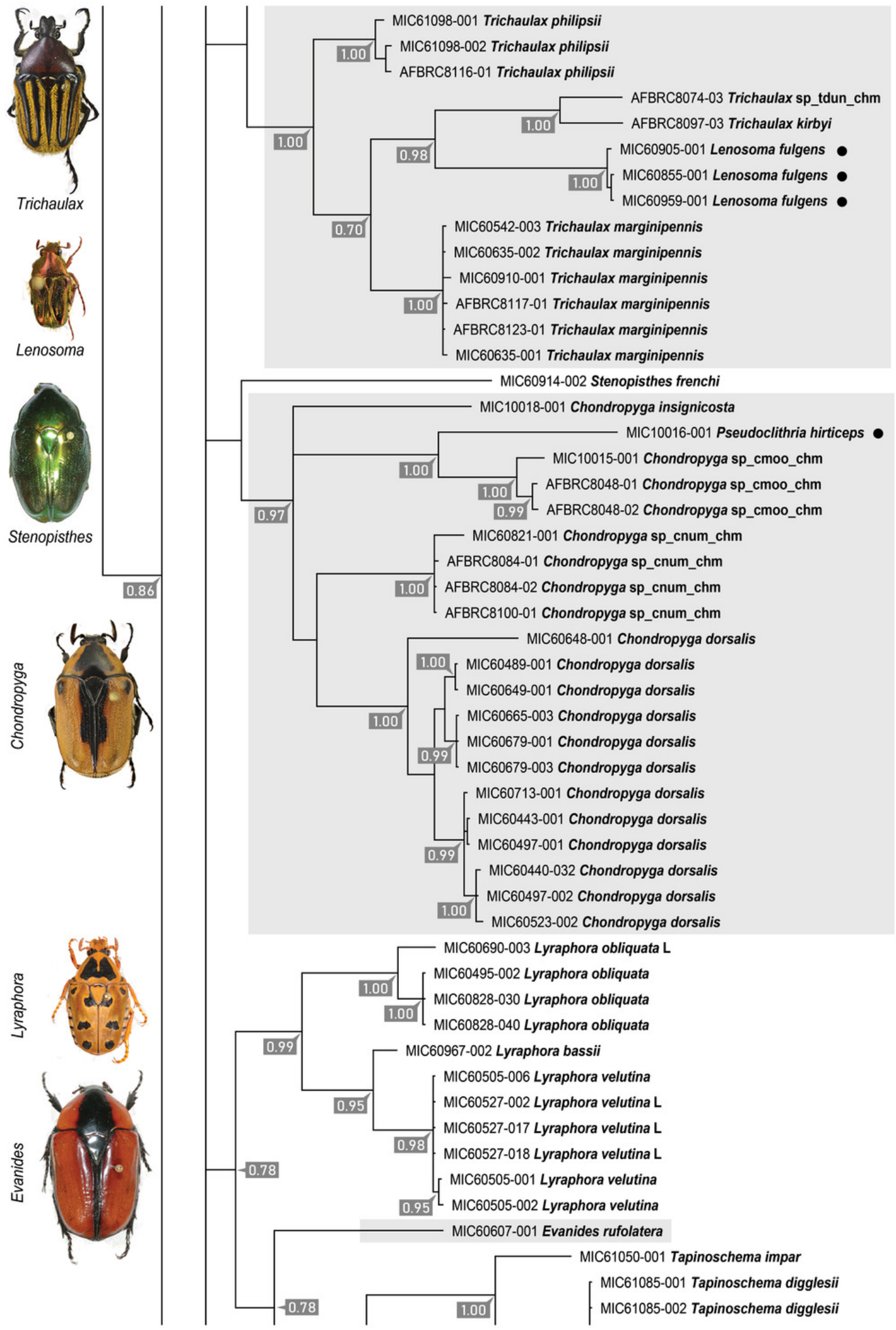




\section{Figure 4}

Complete Bayesian tree, part 3 of 6 .

Support values (posterior probabilities) are shown at nodes only if $\geq 0.70$. Closed circles indicate taxa whose placement in the tree was unexpected, rendering another genus paraphyletic. 

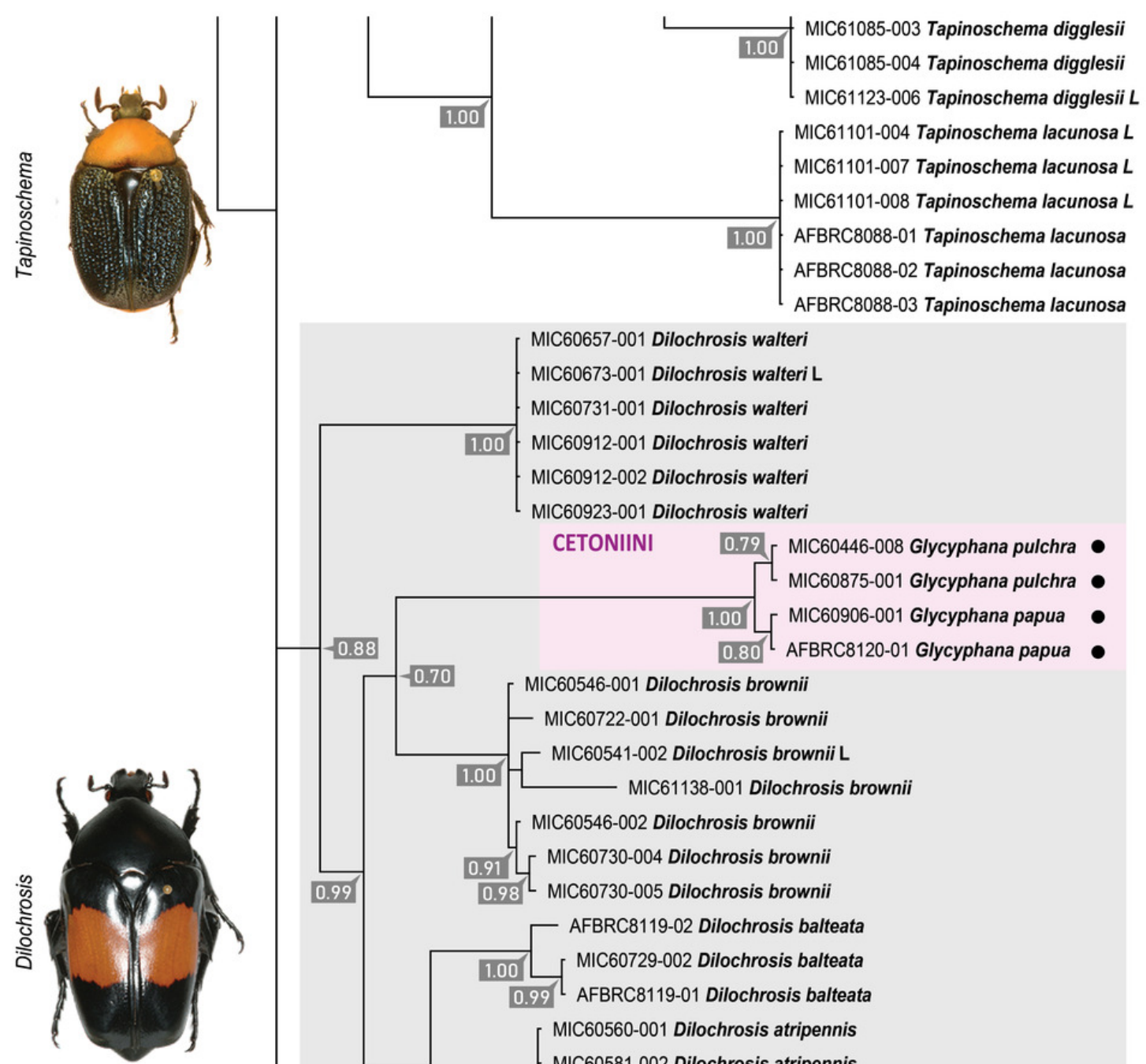

0.990 .98 MIC60730-005 Dilochrosis brownii

- AFBRC8119-02 Dilochrosis balteata

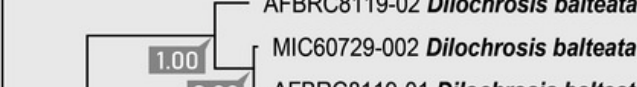

0.99 AFBRC8119-01 Dilochrosis balteata

[ MIC60560-001 Dilochrosis atripennis

MIC60581-002 Dilochrosis atripennis

MIC60656-003 Dilochrosis atripennis L

MIC60656-004 Dilochrosis atripennis L

MIC60659-001 Dilochrosis atripennis

1.00 MIC60661-003 Dilochrosis atripennis

MIC60578-002 Dilochrosis atripennis

- MIC60565-002 Dilochrosis atripennis

- MIC60577-001 Dilochrosis atripennis

MIC60567-001 Dilochrosis atripennis

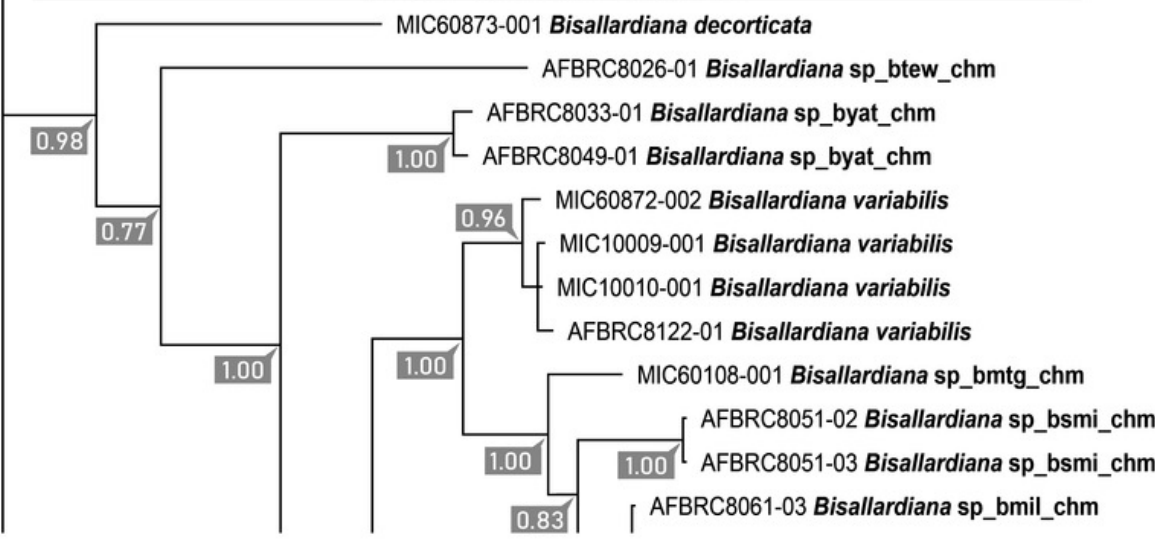




\section{Figure 5}

Complete Bayesian tree, part 4 of 6 .

Support values (posterior probabilities) are shown at nodes only if $\geq 0.70$. Closed circles indicate taxa whose placement in the tree was unexpected, rendering another genus paraphyletic. 

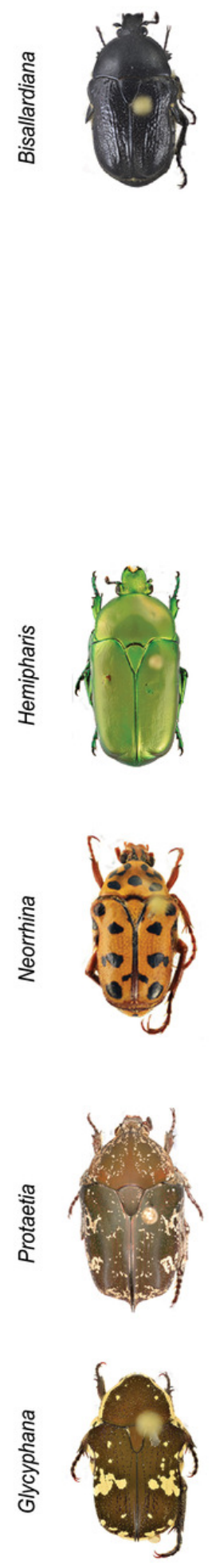

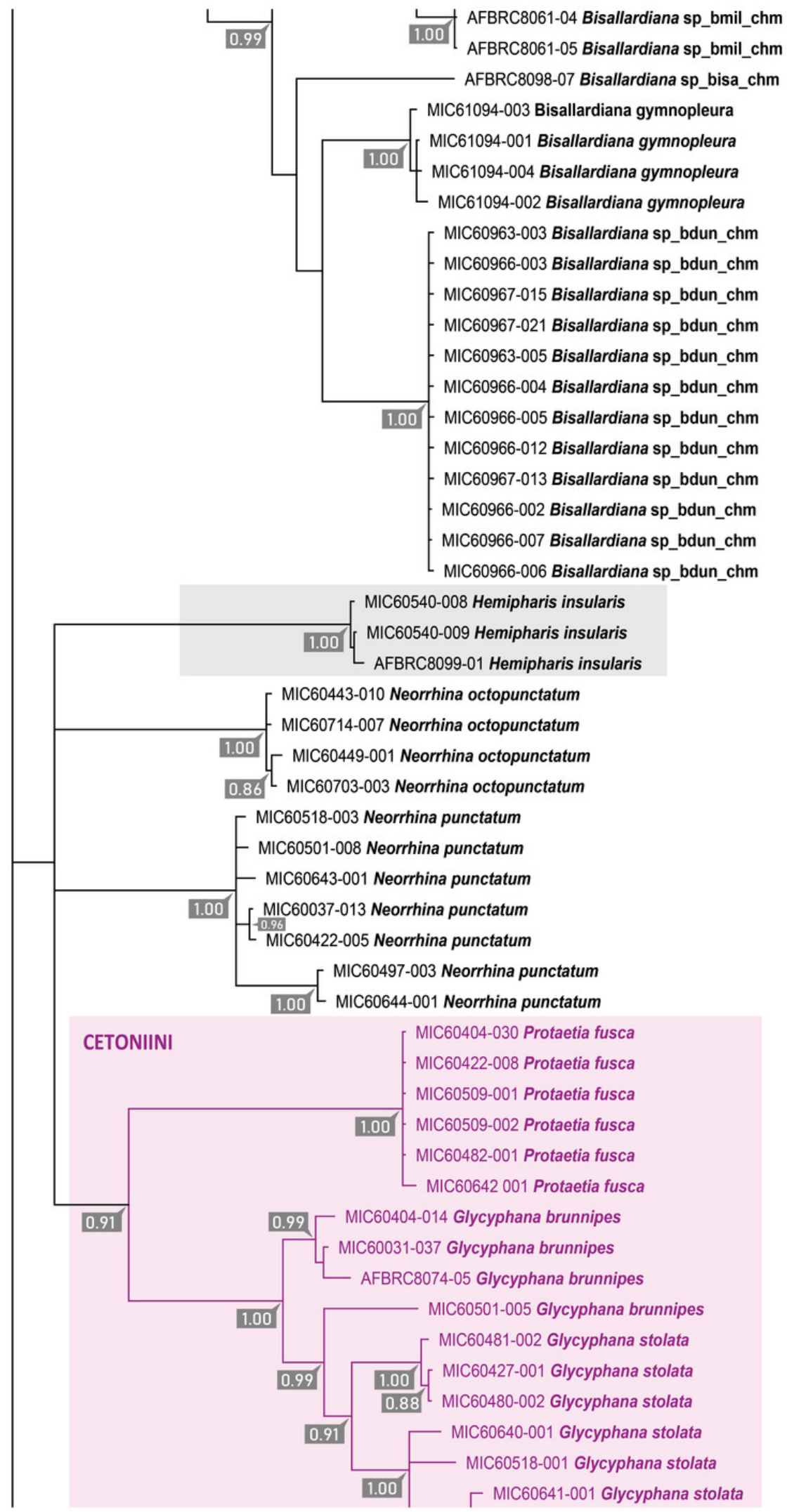




\section{Figure 6}

Complete Bayesian tree, part 5 of 6 .

Support values (posterior probabilities) are shown at nodes only if $\geq 0.70$. Closed circles indicate taxa whose placement in the tree was unexpected, rendering another genus paraphyletic. 

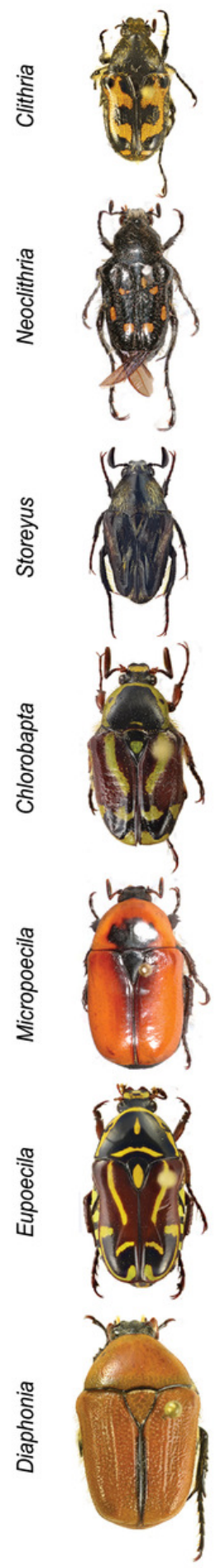

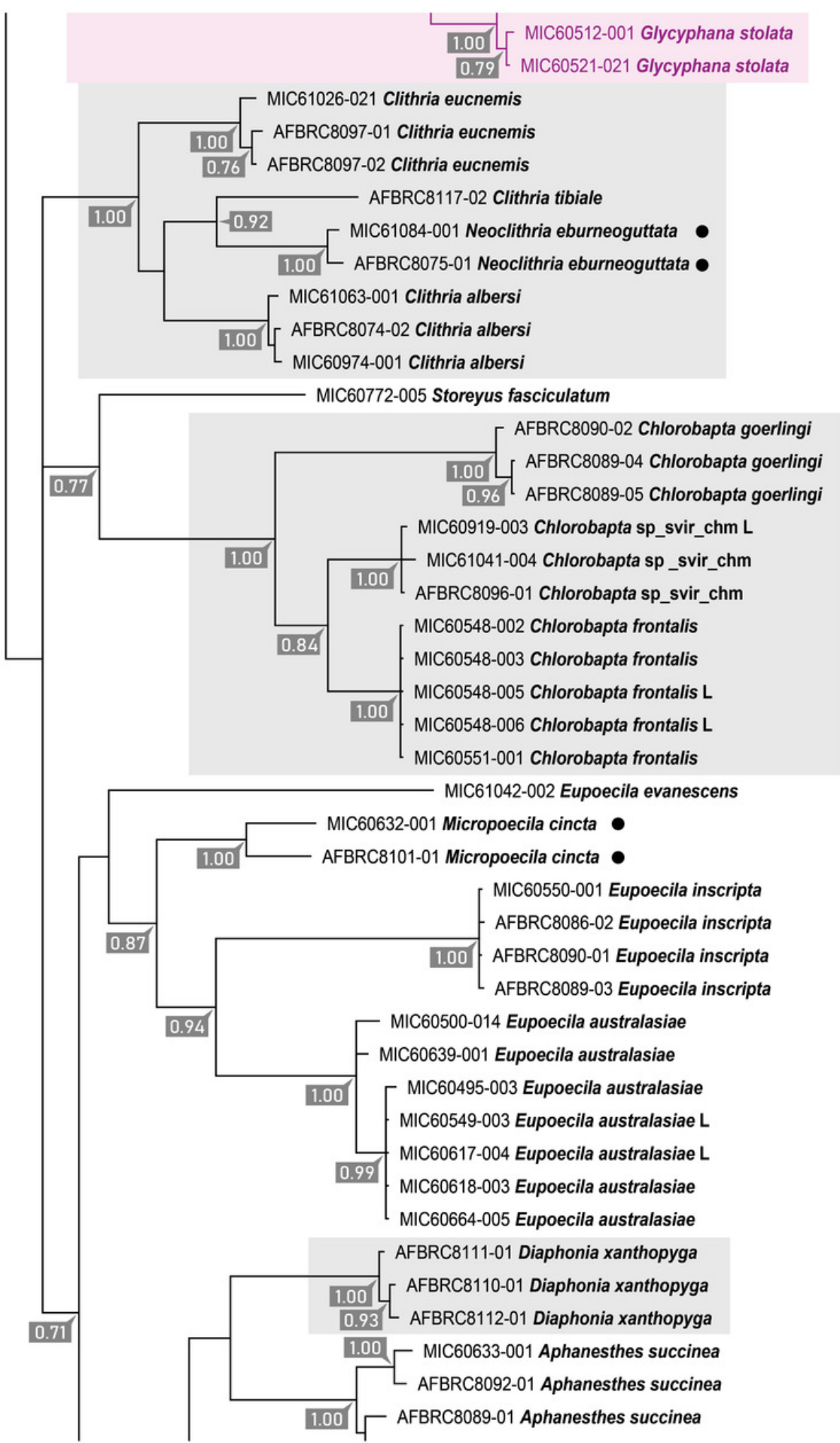


Figure 7

Complete Bayesian tree, part 6 of 6 .

Support values (posterior probabilities) are shown at nodes only if $\geq 0.70$. Closed circles indicate taxa whose placement in the tree was unexpected, rendering another genus paraphyletic. 

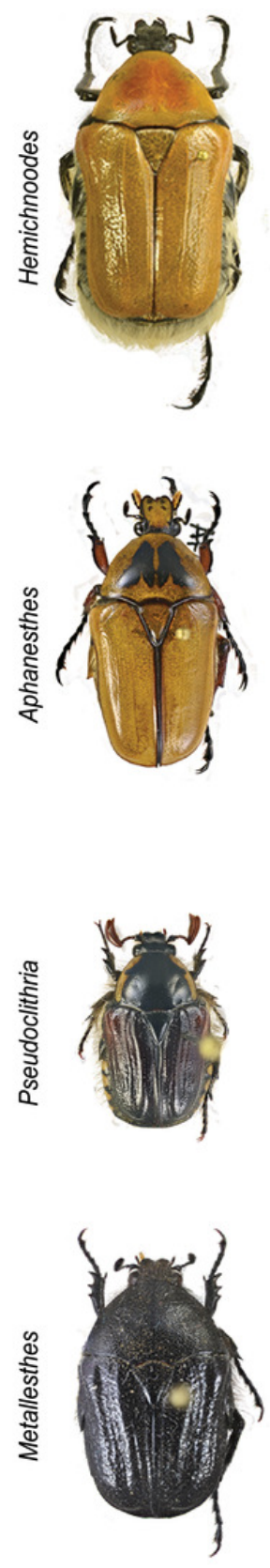

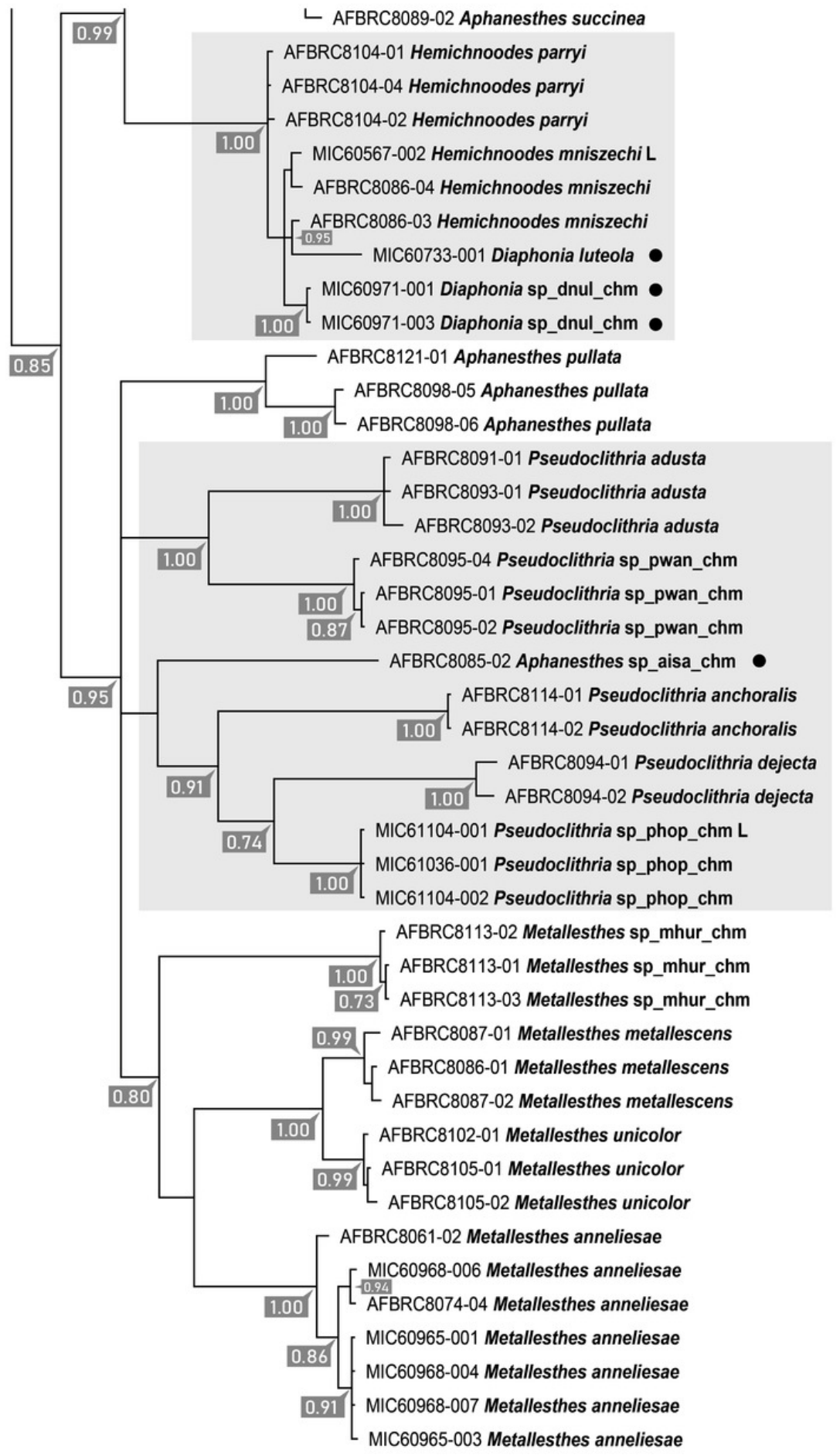


Table $\mathbf{1}$ (on next page)

Previous DNA-based studies of Cetoniinae. 


\begin{tabular}{|c|c|c|c|c|c|}
\hline Reference & $\begin{array}{c}\text { Number } \\
\text { of } \\
\text { cetoniine } \\
\text { samples }\end{array}$ & $\begin{array}{c}\text { Number of } \\
\text { cetoniine } \\
\text { species } \\
\text { sampled } \\
\text { (Australian) }\end{array}$ & $\begin{array}{l}\text { Gene regions } \\
\text { sampled }\end{array}$ & Taxon focus & Study purpose \\
\hline Ahrens et al. (2007) & 11 & $2(0)$ & COI, 16S, 28S & Scarabaeidae & Larval-adult association \\
\hline Ahrens et al. (2008) & 8 & $8(1)$ & COI, 16S, 28S & Sericini & Higher-level phylogeny \\
\hline Ahrens et al. (2011) & 7 & $7(0)$ & COI, 16S, 28S & Hopliini & Higher-level phylogeny \\
\hline Ahrens et al. (2013) & 230 & $1(0)$ & COI, ITS1 & $\begin{array}{l}\text { Cetonia aurata } \\
\text { complex }\end{array}$ & Phylogeography, species-level taxonomy \\
\hline Audisio et al. (2008) & 26 & $1(0)$ & $\mathrm{COI}$ & Osmoderma & Species -level taxonomy \\
\hline Audisio et al. (2009) & 26 & $5(0)$ & $\mathrm{COI}$ & Osmoderma & Species -level taxonomy \\
\hline Gunter et al. (2016) & 15 & $15(15)$ & COI, 16S, 12S, 28S & Scarabaeinae & Higher-level phylogeny \\
\hline Han et al. (2017) & 16 & $3(0)$ & COI & Osmoderma & Species-level taxonomy \\
\hline $\begin{array}{l}\text { Hendrich et al. } \\
(2015)\end{array}$ & 70 & $14(0)$ & $\mathrm{COI}$ & $\begin{array}{l}\text { European } \\
\text { Coleoptera }\end{array}$ & DNA barcoding \\
\hline Kim et al. (2013) & 1 & $1(0)$ & mitogenome & $\begin{array}{l}\text { Protaetia } \\
\text { brevitarsis }\end{array}$ & Genomics \\
\hline Landvik et al. (2013) & 7 & $1(0)$ & $\mathrm{COI}$ & Osmoderma & Species identification \\
\hline Lee et al. (2015) & 50 & $5(0)$ & COI, 16S & Dicronocephalus & Species-level phylogeny \\
\hline $\begin{array}{l}\text { McKenna et al. } \\
(2015)\end{array}$ & 5 & $5(1 ?)$ & 28S, CAD & $\begin{array}{l}\text { Staphyliniformia, } \\
\text { Scarabaeiformia }\end{array}$ & Higher-level phylogeny \\
\hline Philips et al. (2016) & 12 & $11(0)$ & COI, 28S & Trichiotinus & Species-level phylogeny \\
\hline Seidel (2018) & 29 & $5(0)$ & $\mathrm{COI}$ & Eudicella & Species-level taxonomy \\
\hline Sipek et al. (2016) & 130 & $125(2)$ & COI, 16S, 28S & Cetoniinae & Higher-level phylogeny \\
\hline Song et al. (2018) & 4 & $4(0)$ & 5 mitogenomes & Scarabaeidae & Genomics, higher-level phylogeny \\
\hline $\begin{array}{l}\text { Svensson et al. } \\
\text { (2009) }\end{array}$ & 38 & $5(0)$ & $\mathrm{COI}$ & Osmoderma & Species identification \\
\hline $\begin{array}{l}\text { Vondracek et al. } \\
\text { (2018) }\end{array}$ & 65 & $15(0)$ & COI, CytB & Potosia & Species-level taxonomy \\
\hline Zauli et al. (2016) & 27 & $1(0)$ & $\mathrm{COI}$ & Osmoderma & Species-level taxonomy \\
\hline
\end{tabular}




\section{Table 2 (on next page)}

Results of RESL clustering for species showing $>2 \%$ maximum uncorrected intraspecific distance. 


\begin{tabular}{|c|c|c|c|c|}
\hline Species & $\begin{array}{l}\text { Number of } \\
\text { specimens } \\
\text { analysed }\end{array}$ & $\begin{array}{c}\text { Maximum } \\
\text { uncorrected } \\
\text { intraspecific } \\
\text { distance }\end{array}$ & $\begin{array}{c}\text { Number of } \\
\text { RESL OTUs }\end{array}$ & $\begin{array}{l}\text { Number of } \\
\text { BOLD BINs }\end{array}$ \\
\hline Aphanesthes pullata & 3 & $6.20 \%$ & 2 & 2 \\
\hline Chondropyga dorsalis & 12 & $6.09 \%$ & 4 & 4 \\
\hline $\begin{array}{l}\text { Glycyphana } \\
\text { (Glycyphaniola) } \\
\text { brunnipes }\end{array}$ & 4 & $5.61 \%$ & 2 & 2 \\
\hline $\begin{array}{l}\text { Glycyphana } \\
\text { (Glycyphaniola) stolata }\end{array}$ & 8 & $5.52 \%$ & 4 & 4 \\
\hline Neorrhina punctatum & 7 & $3.27 \%$ & 2 & 2 \\
\hline Micropoecila cincta & 2 & $4.84 \%$ & 2 & 2 \\
\hline Dilochrosis brownii & 7 & $4.20 \%$ & 2 & 2 \\
\hline Lyraphora obliquata & 4 & $3.76 \%$ & 2 & 2 \\
\hline Aphanesthes succinea & 4 & $2.51 \%$ & 2 & 2 \\
\hline $\begin{array}{l}\text { Chondropyga } \\
\text { "sp_cmoo_chm" }\end{array}$ & 2 & $2.87 \%$ & 2 & 2 \\
\hline Eupoecila australasiae & 7 & $2.71 \%$ & 1 & 2 \\
\hline Metallesthes anneliesae & 7 & $2.24 \%$ & 2 & 2 \\
\hline Dilochrosis balteata & 3 & $2.15 \%$ & 2 & 1 \\
\hline
\end{tabular}

1 